\title{
A brief overview of thoracic surgery in the United States
}

\author{
Catherine T. Byrd, Kiah M. Williams, Leah M. Backhus \\ Division of Thoracic Surgery, Department of Cardiothoracic Surgery, Stanford University School of Medicine, Stanford, CA, USA \\ Contributions: (I) Conception and design: All authors; (II) Administrative support: None; (III) Provision of study materials or patients: None; (IV) \\ Collection and assembly of data: All authors; (V) Data analysis and interpretation: All authors; (VI) Manuscript writing: All authors; (VII) Final \\ approval of manuscript: All authors. \\ Correspondence to: Leah M. Backhus, MD, MPH. Stanford University, 300 Pasteur Drive, Falk Building, Stanford, CA 94305, USA. \\ Email: lbackhus@stanford.edu.
}

\begin{abstract}
The 331 million people of the United States are served by a complex and expensive healthcare system that accounts for nearly $18 \%$ of the country's gross domestic product. Over $90 \%$ of patients are insured by private or government-funded plans, but despite high coverage and unusually high healthcare spending, vast disparities exist within the United States population based on demographics in terms of diagnosis, treatment, and outcomes of disease. Thoracic surgeons in the United States are trained to treat patients with diseases of the chest in the operative and perioperative settings, and can accomplish this training through multiple highly competitive pathways. Thoracic surgeons perform an average of 135 operations each per year which address diseases of the lungs, trachea, esophagus, chest wall, mediastinum, and diaphragm. Video assisted thoracoscopic surgeries are the most commonly performed procedures, which are primarily completed to treat lung cancer. Lung cancer is the deadliest and second most prevalent malignancy in the United States, with over 200,000 new cases expected this year. In addition to encouragement of smoking cessation and more attention to air pollutants, increased access to lung cancer screening has significantly expedited diagnosis and reduced mortality from lung cancer in the last several years. Thoracic surgeons in the United States are tasked with treating common yet highly morbid diseases of the chest in a patient population that is diverse in terms of race, socioeconomic status, and healthcare insurance coverage. As the population ages and a shortage of thoracic surgeons looms, the importance of early diagnosis, skillful surgical management, and attention to the disparities that exist in our system cannot be overstated.
\end{abstract}

Keywords: Thoracic surgery; United States; delivery of health care; lung neoplasms; healthcare disparities

Submitted Sep 14, 2021. Accepted for publication Dec 09, 2021.

doi: $10.21037 /$ jtd-21-1504

View this article at: https://dx.doi.org/10.21037/jtd-21-1504

\section{Introduction}

The United States of America is a country of 331 million people (1). It is comprised of 50 states that stretch across 3.8 million square miles (2) representing a highly diverse population measured by race and ethnicity, socioeconomics, and local resources. Given the vast nature of the country and the complex healthcare delivery systems, there is significant diversity within thoracic surgery in the United States (U.S.). This review describes a general framework of how thoracic surgery is practiced in the U.S. within its complex healthcare system, including how one becomes a thoracic surgeon capable of providing such care. We also discuss areas of strength and weaknesses within the field, and provide a general overview of the most commonly treated disease by thoracic surgeons in the U.S.-lung cancer.

Lung cancer is the second most prevalent cancer in both men and women in the U.S. and the number one cause of cancer-related mortality (3). There will be an estimated 235,760 new diagnoses of lung cancer in the U.S. in 2021 (4). Of new cases, $17.8 \%$ are diagnosed with local disease, $22 \%$ are diagnosed at the regional stage, and $56 \%$ are diagnosed 
with distant disease (4). The majority of patients undergo surgical therapy including $76.7 \%$ of those with stage I disease, and $83.8 \%$ of those with stage II disease (5).

\section{Overview of healthcare in the U.S.}

It is impossible to provide a review of any medical specialty or medical condition without an appreciation of the healthcare environment within which such care is being delivered. The modern U.S. healthcare system evolved throughout the $20^{\text {th }}$ century, mainly within the private sector without substantial government collaboration. This led to the development of several separate healthcare delivery structures that sometimes work in partnership (6). Overall, local institutions administer healthcare services through private practices, for-profit hospitals and institutions, nonprofit hospitals, and government-funded programs (7).

Payment for healthcare services in the U.S. is uniquely complicated and expensive. In 2019, the U.S. spent $17.7 \%$ of its gross domestic product (approximately 3.8 trillion U.S. dollars) on healthcare (8). This is one of the highest healthcare expenditures (compared to a nation's gross domestic product) of any nation throughout the globe (6). Health insurers pay for most of these healthcare expenses (73\%), the majority of which goes directly to clinical care$31 \%$ for hospital care and $20 \%$ for physician and clinical services (9).

Health insurance in the U.S. consists of a mix of privately funded and government-funded programs (10). Ninetytwo percent of the U.S. population has some form of health insurance. The most common health insurance coverage is privately funded employer-based insurance (56.4\%). An individual may buy other private coverage through a federal or state marketplace $(10.2 \%)$ or the uniformed services (2.6\%). There is a public option for health insurance coverage, utilized by $34 \%$ of the population. The public option is administered through Medicare (for those age 65 and older or on long-term disability), Medicaid (for those under 65 who fall below a poverty threshold), or a public insurance for children called Children's Health Insurance Program. Lastly, the government also funds a separate insurance program for veterans of the U.S. military (10).

Approximately $8 \%$ of the nation's population, 29 million people, are uninsured (10). This percentage decreased from $20 \%$ partially through codification of the 2010 Patient Protection and Affordable Care Act (10). The legislation allowed for the creation of state-based health insurance exchanges or federal government-based marketplaces to permit direct-to-consumer purchase of private insurance. It also provided the option for states to expand Medicare to those under 65 years of age who also earned below $133 \%$ of the federal poverty level (11).

Despite the U.S.' heavy investment in healthcare, life expectancy in the U.S. is lower than many other industrialized countries (10). In fact, in 2020, life expectancy fell by 1.5 to 77.3 years ( $74 \%$ of this decline is secondary to COVID-19) (12). Of note, 27 of 29 examined countries across Europe and the Americas demonstrated a decrease in life expectancy in 2020. However, the U.S. demonstrated the largest decrease in life expectancy from 2019 to 2020 of all examined countries (13). Historically the top 10 causes of death in the U.S. are heart disease, malignancy, accidents, chronic lower respiratory diseases, cerebrovascular disease, Alzheimer's disease, diabetes mellitus, influenza/pneumonia, kidney disease, and suicide (14). Within the malignancy category, the deadliest cancer in the U.S. is lung cancer, accounting for an estimated 131,880 deaths in 2021 alone (3).

\section{General overview of thoracic surgery in the U.S.}

Thoracic surgeons in the U.S. are responsible for the operative and perioperative care of those with surgical diseases of the chest (15). This includes surgery for emphysema, swallowing difficulties, gastroesophageal reflux disease, tumors (lung, esophagus, chest wall, mediastinum), tracheal anomalies, diaphragm disease, end stage heart or lung disease requiring transplantation, and benign chest wall abnormalities $(15,16)$. Benign chest wall conditions such as pectus excavatum are most commonly treated in adolescence by pediatric surgeons in the U.S. Thoracic surgeons are involved when adults with pectus excavatum require revision for recurrence or for the small percentage that require primary repair (16). Those that require revision for recurrence are best served with a modified Ravitch repair while adults undergoing primary repair are able to undergo a modified Nuss repair $(16,17)$.

Approximately 530,000 general thoracic surgery cases are performed yearly in the U.S. by around 4,000 cardiothoracic surgeons (18). Most of these surgeons are male (92\%), with an average age of 56 years (19). It is estimated that the average thoracic surgeon performs 135 cases yearly (18). The most common procedures performed are video-assisted thoracoscopic surgery (VATS) lobectomy, followed by VATS wedge resection, VATS decortication, laparoscopic paraesophageal hernia repair, Ivor-Lewis Esophagectomy (open or minimally invasive), mediastinoscopy with or 
without biopsy, and laparoscopic Nissen fundoplication (20). Most thoracic surgeons perform these procedures through a hospital-based practice (44.8\%) or academic/universitybased practice $(33.6 \%)$. The remaining surgeons are in private practice or employed by the government (19).

Throughout the U.S., approximately $50 \%$ of thoracic surgery is performed by general surgeons (21). Thoracic surgeons perform the majority of complex thoracic surgery procedures at academic and university-based practices, while general surgeons perform most of the thoracic surgery cases in community hospitals (21). As examined by Schipper et al. (22), in any clinical setting, patients who undergo pneumonectomy, lobectomy, limited lung resection, or decortication performed by thoracic surgeons have significantly lower mortality as compared to general surgeons or cardiothoracic surgeons that mainly perform cardiac surgery. However, when adjusted by surgeon volume, this advantage disappears for those undergoing pneumonectomy or decortication. The advantage is still present for those undergoing lobectomy and limited lung resection. Thoracic surgeons also have lower morbidity overall and on adjusted analysis (22). This may be associated with the fact that thoracic surgeons are more likely than other surgeons to perform lung procedures using minimally invasive techniques (odds ratio 1.57, 95\% CI: 1.36-1.81) (23). Specifically, VATS lobectomy and VATS segmentectomy are associated with fewer complications, lower risk of 30-day mortality, and shorter length of stay as compared to open lobectomy or segmentectomy (23).

\section{Thoracic surgery training in the U.S.}

Unlike many other countries, the U.S. has combined training for cardiac and thoracic surgery for the specialty of Cardiothoracic Surgery governed by the American Board of Thoracic Surgery (ABTS). There are three main pathways to becoming a thoracic surgeon in the U.S. (24). In the Traditional Pathway, medical school graduates complete five clinical years of general surgery training before entering a 2-3-year fellowship to specialize in cardiothoracic surgery. These physicians may be certified in general surgery by the American Board of Surgery and in thoracic surgery by the ABTS. In the Integrated (I-6) Pathway, trainees complete six years of cardiothoracic surgery immediately after medical school. They are only eligible for certification in thoracic surgery through the ABTS. In the third pathway $(4+3)$, medical school graduates complete four clinical years of general surgery followed by three years of cardiothoracic surgery residency, all within the same institution. These physicians are also eligible for board certification in both general surgery and thoracic surgery (24). Several residents also consider additional dedicated research time (commonly 2 years) during their training. Within I- 6 training programs, $60 \%$ of residents may choose to take optional dedicated research time, $18 \%$ are required to take research time, and $17 \%$ have no option for dedicated research time. Among the traditional pathway trainees, approximately $69 \%$ performed some type of research during their general surgery training (25). Regardless of research time and across all three training paradigms, residents must complete requisite case numbers for either a cardiac or thoracic track weighted towards their anticipated field of practice.

ABTS certification confers the ability for diplomates to then perform either cardiac surgery, thoracic surgery, or both according to their local scope of practice. $30-42 \%$ of cardiothoracic surgeons are estimated to practice thoracic surgery exclusively with another $31-38 \%$ practicing both cardiac and thoracic surgery (26-28). Among academic medical centers, the majority of cardiothoracic faculty will have a clinical practice dedicated solely to either cardiac or thoracic surgery.

Several studies have predicted a workforce shortage in cardiothoracic surgery in the U.S. by the year 2035 . Moffatt-Bruce et al. projects a $61 \%$ increased annual demand for thoracic surgical procedures from 2010 to 2035 given our aging patient population that will likely require more interventions (18). At the same time, there has been a notable decrease in the number of cardiothoracic surgeons graduating from training programs combined with aging of our existing physician population creating a predictable supply deficit in the thoracic surgical workforce (18).

Despite concerns of declining applications to thoracic surgery training programs (29), U.S. thoracic surgery remains one of the most competitive training programs to enter. In 2021, $100 \%$ of the thoracic surgery fellowship positions were filled (91 positions). There were 154 graduating general surgery residents who applied for these 91 spots, leaving $40 \%$ of applicants without a position (30). For the I-6 programs in 2019, there were only 36 positions offered, with 209 medical school applicants vying for the positions (31).

The development of I-6 programs has led to an increase in the number of well-trained cardiothoracic surgeons joining the field (32). This almost accounts for the decline in the number of traditional pathway positions since the inception of I-6 programs, from 130 traditional pathway 
positions in 2008 to 91 in 2021 (30,32). However, given the projected workforce shortage in cardiothoracic surgery, a significant focus has been placed on recruiting bright medical school and general surgery applicants through mentorship and programs to increase exposure $(33,34)$. This is especially necessary given that operative cardiothoracic surgery experience has declined within general surgery residencies (35). Though continuing to increase the number of training positions would help address the workforce shortage, an emphasis also must be placed on attrition within the field. Twenty-six percent of surgeons considered leaving the field in 2018, many of whom cited that the job demanded too much of their time and that they felt significant stress (36). There were also concerns regarding inadequate mentoring and career advancement (36). It is clear that innovative solutions to recruit new surgeons and to improve the culture of support for mid-career surgeons are necessary to address the workforce shortage.

\section{Areas of strength}

The field of thoracic surgery in the U.S. has seen a push to incorporate new training paradigms and technologies. One training technique that the U.S. has embraced is that of simulation. The Thoracic Surgery Directors Association (TSDA), a collaboration of cardiothoracic surgery residency program directors, began offering boot camps for cardiothoracic surgery trainees in 2008 (37). The Society of Thoracic Surgeons now administers this program, which fulfills the simulation requirement dictated by the ABTS and allows one-on-one training in technical thoracic skills such as bronchoscopy, mediastinoscopy, open lobectomy and hilar dissection, and robotic surgery (37). Nationwide simulation courses and training in individual residency programs have demonstrated benefits. Participants have higher ABTS certification exam pass rates and perform better in true clinical scenarios (38).

Additionally, The Thoracic Surgery Residents Association (TSRA), developed in 1997 and overseen by the TSDA, has become a principal resource for cardiothoracic surgery trainees in North America (39). Over the past 10 years, this collection of residents has published six textbooks and five reference guides that communicate foundational concepts and surgical techniques. They also disseminate information from leaders in cardiothoracic surgery through their podcast, the TSRA Podcast Series. In the podcast, trainees and skillful academic attendings examine clinical topics and appropriate management strategies (39).

\section{Areas for improvement}

Despite our innovation and healthcare expenditures, there are significant healthcare disparities within the U.S. For example, life expectancy differs significantly across races. Life expectancy in the Hispanic community is 78.8 years; in the non-Hispanic White community, it is 77.6 years, while it is 71.8 years in the non-Hispanic Black community (12). Concerning the uninsured rate, in $2019,16.7 \%$ of the Hispanic population was uninsured, $9.6 \%$ of the Black population was uninsured, $6.2 \%$ of the Asian population was uninsured, and $5.2 \%$ of the non-Hispanic White population was uninsured (10). Disparities in adhering to guidelineconcordant surgical cancer care are present across all aspects of surgery. Racial minorities and those living in more rural areas are less likely to receive guideline-concordant care and have worse cancer-specific survival (40).

Specifically, within the thoracic surgery space, increased racial residential segregation is associated with higher lung cancer mortality for black patients (a 10\% difference) (41). When adjusted for differences in stage at diagnosis, socioeconomic status, and marital status, there are still unexplained differences in lung cancer mortality along racial divides (42). Black patients with esophageal cancer are less likely to undergo surgery than their white counterparts despite resectable disease. Unfortunately, there is an associated demonstrated survival cost (43). If patients undergo esophagectomy, reduced survival is no longer associated with race on adjusted analysis but is closely linked with socioeconomic status (44). As stated earlier, because the U.S. healthcare system operates on an ill-defined framework mainly at the local level, it is difficult to enact systems-wide change to address such disparities.

\section{Lung cancer: the most commonly treated disease by thoracic surgeons in the U.S.}

There are an estimated 222,520 surgical operations for lung cancer annually (18). The following operative and perioperative outcomes for lung cancer surgery were examined specifically within the Medicare population (those 65 years of age and older) and were performed most commonly by thoracic surgeons that contribute data to the Society of Thoracic Surgeons database. These patients most commonly undergo lobectomy $(68.2 \%)$ or wedge resection (18.1\%) (45). These procedures are usually performed minimally invasively (VATS) and only $7 \%$ are performed robotically $(45,46)$. The average operative time is $234-242$ minutes $(45,47)$. Postoperatively approximately 
14-15\% experience atrial arrhythmia, $8.5 \%$ require a blood transfusion, 4\% develop pneumonia, 4\% require reintubation, $3-4 \%$ require unanticipated reoperation, $3 \%$ experience delirium, and $1 \%$ experience acute kidney injury $(45,47,48)$. There is a lower odds of morbidity for those that undergo anatomic lung resection for lung cancer if performed by cardiothoracic surgeons as compared to general surgeons (adjusted odds ratio 0.82, $\mathrm{P}=0.011$ ) per the American College of Surgeons National Surgical Quality Improvement Program database (49). Length of stay for this index operation is 3-7 days, with an average of 5 days $(45,47)$. There is an estimated $1.7 \%$ operative mortality $(47)$. The overall cost of the hospitalization associated with this index operation is approximately $\$ 32,000(45,47)$. Yet, even within these ranges, there is a wide degree of variability in clinical outcomes based on surgeon volume, center volume, access to care (e.g., tertiary hospitals, advanced imaging, post-treatment surveillance) and insurance status. For example, insurance status impacts the odds of a patient even receiving surgery for early stage lung cancer. Using the privately insured as the reference group, the medicare population and the uninsured population were both found to have a lower odds of undergoing surgery (0.53 and 0.50 , respectively). This was associated with worse 5-year overall survival (50).

Lung cancer-specific 5-year survival in the U.S. is $59.8 \%$ for those with localized disease, $32.9 \%$ for those with regional disease, and $6.3 \%$ for those with distant metastases (4). Unfortunately, lung cancer-specific 5-year survival is only $21.7 \%$ when examined across all stages (4). An estimated 131,880 people will die from this disease in 2021 in the U.S. $(3,4)$. Five-year survival is higher in some Asian countries (33\% in Japan, 25\% in the Republic of Korea) (51) potentially secondary to early adoption of inclusive screening guidelines (younger patients and those with shorter smoking histories are screened) (52). The U.S. recently updated screening guidelines that more closely reflect those countries' guidelines.

Despite these grim statistics, mortality from lung cancer in the U.S. has been decreasing since $1991(3,4,53)$. From a preventive health standpoint, some of this improvement is attributed to an increase in regulations to reduce air pollutants, smoking cessation programs, and the implementation of lung cancer screening programs (3,53). The U.S. Preventive Services Task Force (USPSTF) initially set forth lung cancer screening recommendations in 2013 (54-56). Per the National Lung Screening Trial, with 12.3 years of median follow-up examining the impact of low dose computed tomography (LDCT) screening, there is a $23.3 \%$ estimated false positive rate and a $3.1 \%$ overdiagnosis rate, but a $20 \%$ relative risk reduction in lung cancer mortality. The number needed to screen to prevent one death attributable to lung cancer was 303 (56). In the interim, studies examining the effectiveness of screening guidelines have found that these guidelines are associated with a false positive rate of $7.9-49.3 \%$, and an overdiagnosis rate of $0-67.2 \%$. There was no impact on quality of life or increase in anxiety (55).

The USPSTF currently recommends yearly LDCT for lung cancer screening. This recommendation applies to those aged 50-80 with a 20 pack-year smoking history who currently smoke or quit smoking less than 15 years ago (57). The guidelines reflect a recent change lowering the age for inclusion and number of pack years smoked as requirements to increase the number of eligible patients and thereby offer the benefits of screening to a larger population. Data from 2016, 3 years after the first USPSTF screening recommendation, demonstrated that as low as $2 \%$ of those eligible for screening participated (58). However, it was not until 2015 that Medicare consistently covered the costs of screening imaging (58). Six years later, in 2021, we are now seeing the impact of Medicare funded lung cancer screening. As patients become eligible for Medicare enrollment (reach age 65 years), there is a significant increase in the diagnosis of stage I lung cancer (from $8.9 \%$ to $19.1 \%$ ) with a decrease in stage IV lung cancer diagnosis (54.9\% to $41.4 \%)$. This is also associated with a 5 -year disease-specific survival improvement (59). As the U.S. and thoracic surgeons continue to invest in and promote lung cancer screening together, we will likely see an even more drastic improvement in lung cancer mortality.

\section{Conclusions}

Thoracic Surgery in the U.S. operates within a complex and expensive healthcare delivery system with unfortunate healthcare disparities. Despite this, the field continues to innovate new training paradigms to prepare future leaders in the field to provide the best care possible to our patients. Thoracic surgeons are critical in treating the deadliest cancer in the U.S.-lung cancer-and overall have the best outcomes for this disease. We look forward to seeing mortality from this disease continue to decline as we look towards the future (Figure 1). 



Figure 1 Catherine T. Byrd, MD; Kiah M. Williams, MD; and Leah M. Backhus, MD, MPH.

\section{Acknowledgments}

Funding: This work was supported by the National Institute of Health (NIH) (No. R01 HL148185-01).

\section{Footnote}

Provenance and Peer Review: This article was commissioned by the Guest Editor (Alan D. L. Sihoe) for the series "Thoracic Surgery Worldwide" published in fournal of Thoracic Disease. The article has undergone external peer review.

Peer Review File: Available at https://jtd.amegroups.com/ article/view/10.21037/jtd-21-1504/prf

Conflicts of Interest: The authors have completed the ICMJE uniform disclosure form (available at https://jtd.amegroups. com/article/view/10.21037/jtd-21-1504/coif). The series "Thoracic Surgery Worldwide" was commissioned by the editorial office without any funding or sponsorship. CB and LB report that this work was supported by the National Institute of Health (NIH). LB serves as VA Merit Award Principal Investigator, Director at Large, Board of Directors on Society of Thoracic Surgeons. She received consulting fees in Guidepoint Consulting. She serves on an advisory board for Johnson \& Johnson for their engagement of Women in Surgery. There is no clinical interest. For Bristol Myers Squib she has participated in an expert panel to advise them regarding strategies to engage early stage lung cancer patients for immunotherapy. The authors have no other conflicts of interest to declare.
Ethical Statement: The authors are accountable for all aspects of the work in ensuring that questions related to the accuracy or integrity of any part of the work are appropriately investigated and resolved.

Open Access Statement: This is an Open Access article distributed in accordance with the Creative Commons Attribution-NonCommercial-NoDerivs 4.0 International License (CC BY-NC-ND 4.0), which permits the noncommercial replication and distribution of the article with the strict proviso that no changes or edits are made and the original work is properly cited (including links to both the formal publication through the relevant DOI and the license). See: https://creativecommons.org/licenses/by-nc-nd/4.0/.

\section{References}

1. Hartley C, Perry M, Rogers L. A Preliminary Analysis of U.S. and State-Level Results From the 2020 Census. US Census Bureau, 2021.

2. Bureau UC. State Area Measurements and Internal Point Coordinates. The United States Census Bureau. Available online: https://www.census.gov/geographies/referencefiles/2010/geo/state-area.html

3. Siegel RL, Miller KD, Fuchs HE, et al. Cancer Statistics, 2021. CA Cancer J Clin 2021;71:7-33.

4. National Cancer Institute. SEER Cancer Stat Facts: Lung and Bronchus Cancer. SEER Cancer Stat Facts: Lung and Bronchus Cancer. 2021. Available online: https://seer. cancer.gov/statfacts/html/lungb.html

5. Robinson D, Hawthorne S, Zhao L, et al. Treatment 
patterns in non-small-cell lung cancer in USA: results of the CancerMPact Survey 2018. Future Oncol 2020;16:255-62.

6. Rice T, Rosenau P, Unruh LY, et al. United States of America: health system review. Health Syst Transit 2013;15:1-431.

7. De Lew N, Greenberg G, Kinchen K. A layman's guide to the U.S. health care system. Health Care Financ Rev 1992;14:151-69.

8. NHE Fact Sheet I CMS. Available online: https://www. cms.gov/Research-Statistics-Data-and-Systems/StatisticsTrends-and-Reports/NationalHealthExpendData/NHEFact-Sheet

9. Centers for Medicare \& Medicaid Services. Nation's Health Dollar: Where it Came From, Where it Went. .S. Centers for Medicare \& Medicaid Services, 2020. Available online: https://www.cms.gov/Research-StatisticsData-and-Systems/Statistics-Trends-and-Reports/ NationalHealthExpendData/NationalHealthAccountsHist orical

10. Keisler-Starkey K, Bunch LN. U.S. Census Bureau Current Population Reports, P60-271, Health Insurance Coverage in the United States: 2019. U.S. Government Publishing Office, 2020.

11. French MT, Homer J, Gumus G, et al. Key Provisions of the Patient Protection and Affordable Care Act (ACA): A Systematic Review and Presentation of Early Research Findings. Health Serv Res 2016;51:1735-71.

12. Arias E, Betzaida T-V, Ahmad F, et al. Provisional Life Expectancy Estimates for 2020. National Center for Health Statistics (U.S.), 2021. Available online: https:// stacks.cdc.gov/view/cdc/107201

13. Aburto JM, Schöley J, Kashnitsky I, et al. Quantifying impacts of the COVID-19 pandemic through lifeexpectancy losses: a population-level study of 29 countries. Int J Epidemiol 2021; dyab207.

14. National Center for Health Statistics, Heron M. Deaths: Leading Causes for 2018. National Center for Health Statistics, 2021. Available online: https://stacks.cdc.gov/ view/cdc/104186

15. Association of American Medical Colleges. Thoracic Surgery- Careers in Medicine. AAMC Careers in Medicine, 2021. Available online: https://www.aamc.org/ cim/explore-options/specialty-profiles/thoracic-surgery

16. Luu TD, Kogon BE, Force SD, et al. Surgery for Recurrent Pectus Deformities. Ann Thorac Surg 2009;88:1627-31.

17. Jaroszewski DE, Velazco CS. Minimally Invasive Pectus Excavatum Repair (MIRPE) I Elsevier Enhanced Reader.
Oper Tech Thorac Cardiovasc Surg 2018;23:198-215.

18. Moffatt-Bruce S, Crestanello J, Way DP, et al. Providing cardiothoracic services in 2035: Signs of trouble ahead. J Thorac Cardiovasc Surg 2018;155:824-9.

19. Ikonomidis JS, Boden N, Atluri P. The Society of Thoracic Surgeons Thoracic Surgery Practice and Access Task Force-2019 Workforce Report. Ann Thorac Surg 2020;110:1082-90.

20. Society of Thoracic Surgeons DCRI. STS General Thoracic Surgery Executive Summary. 2018. Available online: https://www.sts.org/sites/default/files/documents/ STSThoracic-ExecutiveSummaryFall2018.pdf

21. Cooke DT, Wisner DH. Who Performs Complex Noncardiac Thoracic Surgery in United States Academic Medical Centers? Ann Thorac Surg 2012;94:1060-4.

22. Schipper PH, Diggs BS, Ungerleider RM, et al. The influence of surgeon specialty on outcomes in general thoracic surgery: a national sample 1996 to 2005 . Ann Thorac Surg 2009;88:1566-72; discussion 1572-3.

23. Mehta H, Osasona A, Shan Y, et al. Trends and Outcomes of Thoracoscopic Lobectomy or Segmentectomy: A National Surgical Quality Improvement Project Analysis. Semin Thorac Cardiovasc Surg 2018;30:350-9.

24. The Thoracic Surgery Directors Association. CT Surgery Training Pathways I TSDA. 2012. Available online: https://tsda.org/the-tsda/ct-residency-programs/ctsurgery-training-pathways/

25. Stephens EH, Shah AA, Robich MP, et al. The Future of the Academic Cardiothoracic Surgeon: Results of the TSRA/TSDA In-Training Examination Survey. Ann Thorac Surg 2016;102:643-50.

26. Rosati CM, Koniaris LG, Molena D, et al. Characteristics of cardiothoracic surgeons practicing at the top-ranked US institutions. J Thorac Dis 2016;8:3232-44.

27. Wood DE, Farjah F. Global Differences in the Training, Practice, and Interrelationship of Cardiac and Thoracic Surgeons. Ann Thorac Surg 2009;88:515-22.e5.

28. Wood DE. Cardiothoracic surgery: A specialty divided or as one. J Thorac Cardiovasc Surg 2009;137:1-9.

29. Moffatt-Bruce SD, Ross P, Williams TE. American Board of Thoracic Surgery examination: Fewer graduates, more failures. J Thorac Cardiovasc Surg 2014;147:1464-69.

30. National Resident Matching Program. Match Results Statistics: Thoracic Surgery and Vascular Surgery -2021. National Resident Matching Program, 2021. Available online: https://mk0nrmp3 oyqui6wqfm.kinstacdn.com/wpcontent/uploads/2021/05/Thoracic-Surgery-and-VascularSurgery_AY2022.pdf 
31. Smood B, Nguyen SN, Kelly JJ, et al. Integrated cardiothoracic surgery: Developing a successful residency application. J Thorac Cardiovasc Surg 2020;160:167-74.

32. Bui J, Bennett WC, Long J, et al. Recent Trends in Cardiothoracic Surgery Training: Data from the National Resident Matching Program. J Surg Educ 2021;78:672-8.

33. Williams KM, Hironaka CE, Wang H, et al. Women in Thoracic Surgery Scholarship: Impact on Career Path and Interest in Cardiothoracic Surgery. Ann Thorac Surg 2021;112:302-7.

34. Chan PG, Liang S, Smood B, et al. American Association for Thoracic Surgery Summer Intern Scholarship-Over a decade of experience. J Thorac Cardiovasc Surg 2021. [Epub ahead of print]. doi: 10.1016/j.jtcrs.2021.07.010.

35. Ragalie WS, Termuhlen PM, Little AG. Changes in Thoracic Surgery Experience During General Surgery Residency: A Review of the Case Logs From the Accreditation Council for Graduate Medical Education. Ann Thorac Surg 2016;102:2095-8.

36. Mahoney ST, Strassle PD, Schroen AT, et al. Survey of the US Surgeon Workforce: Practice Characteristics, Job Satisfaction, and Reasons for Leaving Surgery. J Am Coll Surg 2020;230:283-293.e1.

37. Thoracic Surgery Directors Association. 2019 TSDA Boot Camp. Available online: https://tsda.org/the-tsda/bootcamp/boot-camp-archive/2019-tsda-boot-camp/

38. Rowse PG, Dearani JA. Deliberate Practice and the Emerging Roles of Simulation in Thoracic Surgery. Thorac Surg Clin 2019;29:303-9.

39. Brescia AA, Lou X, Louis C, et al. The Thoracic Surgery Residents Association: Past contributions, current efforts, and future directions. J Thorac Cardiovasc Surg. 2021;162:917-27.e5.

40. Zahnd WE, Murphy C, Knoll M, et al. The Intersection of Rural Residence and Minority Race/Ethnicity in Cancer Disparities in the United States. Int J Environ Res Public Health 2021;18:1384.

41. Hayanga AJ, Zeliadt SB, Backhus LM. Residential Segregation and Lung Cancer Mortality in the United States. JAMA Surg 2013;148:37-42.

42. Ellis L, Canchola AJ, Spiegel D, et al. Racial and Ethnic Disparities in Cancer Survival: The Contribution of Tumor, Sociodemographic, Institutional, and Neighborhood Characteristics. J Clin Oncol 2018;36:25-33.

43. Savitch SL, Grenda TR, Scott W, et al. Racial Disparities in Rates of Surgery for Esophageal Cancer: a Study from the National Cancer Database. J Gastrointest Surg
2021;25:581-92.

44. Erhunmwunsee L, Gulack BC, Rushing C, et al. Socioeconomic Status, Not Race, Is Associated With Reduced Survival in Esophagectomy Patients. Ann Thorac Surg 2017;104:234-44.

45. Cowper PA, Feng L, Kosinski AS, et al. Initial and Longitudinal Cost of Surgical Resection for Lung Cancer. Ann Thorac Surg 2021;111:1827-33.

46. Phillips JD, Bostock IC, Hasson RM, et al. National practice trends for the surgical management of lung cancer in the CMS population: an atlas of care. J Thorac Dis 2019;11:S500-8.

47. Medbery RL, Fernandez FG, Kosinski AS, et al. Costs Associated With Lobectomy for Lung Cancer: An Analysis Merging STS and Medicare Data. Ann Thorac Surg 2021;111:1781-90.

48. Fernandez FG, Kosinski AS, Furnary AP, et al. Differential effects of operative complications on survival after surgery for primary lung cancer. J Thorac Cardiovasc Surg 2018;155:1254-1264.e1.

49. Vossler JD, Abdul-Ghani A, Tsai PI, et al. Outcomes of Anatomic Lung Resection for Cancer Are Better When Performed by Cardiothoracic Surgeons. Ann Thorac Surg 2021;111:1004-11.

50. Stokes SM, Wakeam E, Swords DS, et al. Impact of insurance status on receipt of definitive surgical therapy and posttreatment outcomes in early stage lung cancer. Surgery 2018;164:1287-93.

51. Allemani C, Matsuda T, Di Carlo V, et al. Global surveillance of trends in cancer survival: analysis of individual records for 37,513,025 patients diagnosed with one of 18 cancers during 2000-2014 from 322 populationbased registries in 71 countries (CONCORD-3). Lancet 2018;391:1023-75.

52. Triphuridet N, Henschke C. Landscape on CT screening for lung cancer in Asia. Lung Cancer (Auckl) 2019;10:107-24.

53. Yang D, Liu Y, Bai C, et al. Epidemiology of lung cancer and lung cancer screening programs in China and the United States. Cancer Lett 2020;468:82-7.

54. Jonas DE, Reuland DS, Reddy SM, et al. Screening for Lung Cancer With Low-Dose Computed Tomography: Updated Evidence Report and Systematic Review for the US Preventive Services Task Force. JAMA 2021;325:971-87.

55. Jonas DE, Reuland DS, Reddy SM, et al. Screening for Lung Cancer With Low-Dose Computed Tomography: An Evidence Review for the U.S. Preventive Services Task 
Force. Rockville (MD): Agency for Healthcare Research and Quality (US), 2021. (U.S. Preventive Services Task Force Evidence Syntheses, formerly Systematic Evidence Reviews). Available online: http://www.ncbi.nlm.nih.gov/ books/NBK568573/

56. Bradley SH, Shinkins B, Kennedy MP. What is the balance of benefits and harms for lung cancer screening with low-dose computed tomography? J R Soc Med 2021;114:164-70.

57. US Preventive Services Task Force; Krist AH, Davidson
KW, et al. Screening for Lung Cancer: US Preventive Services Task Force Recommendation Statement. JAMA 2021;325:962-70.

58. Pham D, Bhandari S, Pinkston C, et al. Lung Cancer Screening Registry Reveals Low-dose CT Screening Remains Heavily Underutilized. Clin Lung Cancer 2020;21:e206-11.

59. Patel DC, He H, Berry MF, et al. Cancer diagnoses and survival rise as 65-year-olds become Medicare-eligible. Cancer 2021;127:2302-10. A brief overview of thoracic surgery in the United States. J Thorac Dis 2022;14(1):218-226. doi: 10.21037/jtd-21-1504

Cite this article as: Byrd CT, Williams KM, Backhus LM. 